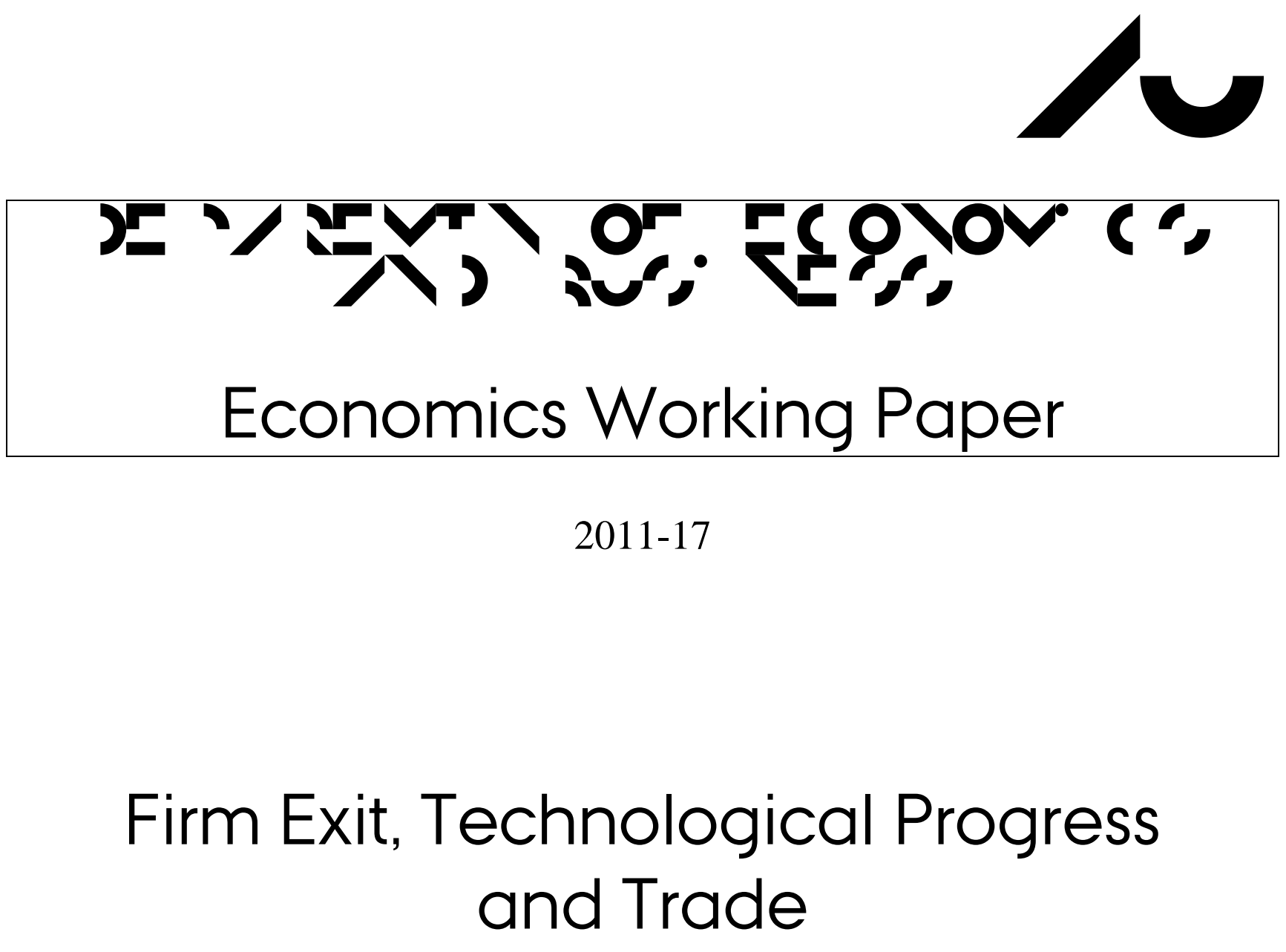

Philipp J.H. Schröder and Allan Sørensen

Department of Economis and Business

Business and Social Sciences

Aarhus University

Bartholins Allé 10, Building 1322

DK-8000 Aarhus C - Denmark

Phone +4589421610

Mail: oekonomi@econ.au.dk

Web: www.econ.au.dk 


\title{
Firm Exit, Technological Progress and Trade
}

\author{
Philipp J.H. Schröder* Allan Sørensen ${ }^{\dagger}$
}

September 2011

\begin{abstract}
The dynamics of export market exit and firm closure have found limited attention in the new heterogeneous-firms trade literature. In fact, several of the predictions on firm survival and exit stemming from this new class of models are at odds with the stylized facts. Empirically, higher productivity firms survive longer, most firm closures are young firms, higher productivity exporters are more likely to continue to export compared to less productive exporters and market exits as well as firm closures are typically preceded by periods of contracting market shares. The present paper shows that the simple inclusion of exogenous economy wide technological progress into the standard Melitz (2003) model generates a tractable dynamic framework that generates endogenous exit decisions of firms in line with the stylized facts. Furthermore, we derive the effects of faster technological progress and trade liberalization on export market exit and firm closure.
\end{abstract}

JEL: F12, F15, O33, L11, L16

Keywords: Intra-industry trade, entry/exit, monopolistic competition, heterogeneous firms, technological change.

\footnotetext{
*Aarhus University, Business and Social Sciences, Department of Economics and Business, Denmark. Tel.: +45 8948 6392, Fax: +45 8948 6197, E-mail: psc@asb.dk.

${ }^{\dagger}$ Aarhus University, Business and Social Sciences, Department of Economics and Business, Denmark. Tel.: +45 8948 6415, E-mail: allans@asb.dk.

Acknowledgements: We wish to thank Poul H. Andersen, Holger Görg, Jørgen Ulff-Møller Nielsen, Horst Raff, Davide Sala and participants at the 12th Göttinger International Economics conference, the 12th ETSG conference and the 25th EEA annual congress for helpful comments and discussions. Philipp Schröder acknowledges financial support from the Tuborg Foundation.

Note: A revised version is forthcoming in the European Economic Review.
} 


\section{Introduction}

While heterogeneous-firms trade theory has a great deal to say about firm entry and their sorting into export markets and market serving modes, it has surprisingly little to add on the phenomenon of export market exit and firm closure. Yet, empirically, exit from markets is as important a phenomenon as entry, and firm-level data permits ample interference on the characteristics of exiting firms. Moreover, since the introduction of Stigler's (1958) survivor principle, firm exit and death has been a central parameter in the study of industrial organization. Most importantly, several of the predictions on exit stemming from the new models (e.g. Melitz, 2003) are at odds with the stylized facts. ${ }^{1}$ Some of the well-established stylized facts on exit derived from microeconomic evidence are: high productivity firms survive longer, most firm closures are young firms, larger size firms have lower exit probabilities, more productive exporters are more likely to continue to export compared to less productive exporters, market exit is typically preceded by a period of contracting market shares and firms are regularly observed to withdraw from some markets while staying active on others; see for example the literature overviews presented in Foster et al. (2001), Greenaway and Kneller (2007), and Wagner $(2007,2011) .^{2}$

The present paper shows that the single modification of including exogenous technological progress into the standard Melitz (2003) model, augmented with Pareto distributed productivities, generates an analytically solvable dynamic framework that preserves all the established novelties of Melitz (2003) while adding endogenous exit decisions of firms in line with the stylized facts. In doing so, the present paper highlights how competition forces are an important transmission channel between technological progress and firm exit dynamics and examines how opening to trade impacts on these forces. With technological progress and vintage capital properties, the arrival of new producers squeezes the market share of existing producers such that incumbent firms will eventually exit the market. This perspective on creative destruction, and in fact the modeling choice of exogenous technolog-

\footnotetext{
${ }^{1}$ In the Melitz (2003) model exit is solely driven by the random death parameter, $\delta$, such that high and low productivity firms (and thus large and small firms) have the same exit probability, low and high productivity exporters are equally likely to continue to export, and a firm exits - if it exits - on all markets simultaneously.

${ }^{2}$ The stylized facts on firm exit and death in fact stem from two branches of literature. Namely, evidence from the Industrial Organization literature, e.g. Jovanovic (1982), Dunne et al. (1988), Caves (1998) or Klepper (2002) and evidence dealing with exporters (and export market exit) in the International Trade literature, see for example Farinas and Ruano (2005), Greenaway and Kneller (2008), Eaton et al. (forthcoming), Colantone and Sleuwaegen (2010), or for an overview Wagner (2011, table 7).
} 
ical progress, is by no means new, but is based on the central contribution of Dasgupta and Stiglitz (1981) to the dynamics of oligopolistic industries.

There are a number of papers that explicitly address issues of dynamics in heterogeneous firms trade settings. Rich exit dynamics are generated by the inclusion of some firm-specific random process affecting productivity, e.g. Irarrazabal and Opromolla (2008) and Arkolakis (2009). Thus, this branch of literature is in this respect similar to the seminal model presented by Hopenhayn (1992). Alternatively, firms may uncover firm-specific innovation advances that secure firm growth or the absence of which causes firm exit once a good innovation draw is lacking, see for example, Atkeson and Burstein (2010) and Costantini and Melitz (2009) who deal with the joint innovation and export decisions of firms. ${ }^{3}$

What these previous works have in common is that exit of firms (be it from a foreign market alone or an actual firm closure) is driven by an intrafirm process, such as a random productivity development, that is paired with a constant firm death probability, as evoked in Melitz (2003). Thus, the driver of firm-level exit behavior is specific to the firm and occurs within the firm. In contrast, what the present paper highlights is a different - but no doubt central - channel of firm exit dynamics initially suggested by Dasgupta and Stiglitz (1981). It is exogenous to the firm, deterministic and specific to the economy. We introduce economy wide technological progress. New firms have, as in a vintage capital model, access to more efficient production methods, while incumbent firms are technologically locked.

There are several advantages of focusing on the competitive pressure channel of technological progress as a driver of firm-level exit dynamics compared to the other approaches discussed in the heterogeneous-firms trade literature. Firstly, the standard assumption of a constant and identical death probability for all firms has little economic foundation, and the specification presented here is able to abandon this assumption altogether. Secondly, while dynamic model extensions based on random process often have to rely on numerical solutions, our dynamic extension of Melitz (2003) remains simple, tractable and based on analytical solutions throughout. Thirdly, technological progress and technological lock-in or lags in technology adoption are well-established phe-

\footnotetext{
${ }^{3}$ In a different line of modeling, Ederington and McCalman (2009) consider endogenous innovation choices by firms, but they focus on the interaction of international trade and the adoption of new technologies in causing industry shakeouts, i.e. large waves of exit. Baldwin and Robert-Nicoud (2007) model technological progress through falling fixed costs over time, yet they only study the entry of firms. Finally, in a recent paper Pflüger and Russek (2011) tackle the exit issue directly by imposing a functional relation between productivity and the exit probability in a Melitz (2003) type model that is able to explore the link between economy wide business conditions and firms default risk.
} 
nomena and appear to be reasonable assumptions to impose on the model. In contrast, an assumption of random productivity developments is somewhat harder to grasp and random reductions in productivity may challenge the basic intuition of innovation, where new production methods are unlikely to replace existing ones, unless they are more efficient.

The modeling choice of vintage capital (and lack of technology upgrade for existing firms) - apart from allowing us to generate endogenous exit is anchored in several strands of literature. Obviously, it relates closely to the vintage capital formulations that have seen renewed popularity in growth theory since the 1990s (see for example the reviews in Aghion and Griffith, 2005, or Boucekkine et al., 2011); the recent developments in the study of equilibrium dynamics of vintage capital formulations by Boucekkine et al. (2005) have underlined the importance and empirical relevance of the approach. ${ }^{4}$ Furthermore, our assumptions on technology can be interpreted as what the organizational science literature refers to as competency traps, where incumbent firms fail to upgrade technologies, see the seminal contribution by Levitt and March (1988). Stark examples of such situations are the late arrival of traditional camera and photographic film producers in the digital age, or the current focus in the motor vehicle industry on improvements of the internal combustion gasoline engine, despite the advent of next generation propulsion systems. Moreover, the literature on technology adoption gives ample empirical evidence. An extensively studied episode of technology adoption comes from the telecommunications equipment industry: Olley and Pakes (1996) provide, apart from their widely cited methodological advances, important evidence that technological change affects industry-wide productivity, inter alia, by inducing the closure of older and relatively unproductive plants. Similarly, the literature on technology diffusion and technology-uselags (e.g. Comin et al., 2008, and Comin and Hobijn, 2010) has established sizable adoption lags of new technologies. Again, this underpins a vintage capital assumption as evoked in the present paper. In fact the theoretical model provided by Comin and Hobijn (2010) to guide their empirical analysis into technology adoption assumes technological vintages for firms and exogenous technological progress, which is similar to the assumptions used in the present model. Finally, the literature on embodied technological change (technological advances that are embodied in new capital goods), highlights the existence of vintage capital properties empirically and theoretically, see e.g. Campbell (1997) or Boucekkine et al. (2003).

\footnotetext{
${ }^{4}$ It goes without saying, that our version of vintage capital is rudimentary in comparison to the specifications used in contemporary growth theory, e.g. Boucekkine et al. (2005).
} 
The paper perhaps closest to ours is that of Haruyama and Zhao (2008), albeit being set in a very different framework. In their model, product or market exit stems from a firm-endogenous decision to improve quality of existing products, where successful quality jumps render former products obsolete. The innovation process is firm-endogenous, labor-absorbing, and the incentive to innovate interacts with trade liberalization via market size. Their model focuses on the interaction of the firm-level innovation process, trade and overall productivity growth. In contrast, our paper focuses on exit dynamics and the competition element in creative destruction, where entry of new and higher productivity varieties marginalizes existing products. Thus, in our paper firms decide endogenously to exit from export markets, not because some specific innovation has rendered their product obsolete, but because their market share has been squeezed so much that further operation is unprofitable. In terms of modeling technology and technological progress, our approach of exogenous technological progress is very similar to that introduced in Luttmer (2007). This paper also considers selection and growth implications, but stays in a closed economy framework, in addition Luttmer (2007) introduces and compares exogenous technological progress with imitation-driven technological progress. Imitation is also at the center of Gabler and Licandro (2007), where firm exit is caused both through the increased competition from imitation and by a firm-specific idiosyncratic productivity shock.

The model we develop is a straightforward extension of Melitz (2003), mapping dynamic firm-level behavior of exit under a situation of continuous technological progress. Progress is modeled as exogenous and continuous improvements in the productivity distribution that firms draw from before entering the market. With this simple assumption future firms will have expected higher productivity and larger market shares on all markets that they enter. Accordingly, potential new entrants realize prior to entry, that they will eventually be ousted from, first the foreign market (if they should choose to export) and eventually the domestic market. They take this expected time of exit (as well as the expected benefits of waiting) into account when deciding whether to enter the industry or not.

The resulting dynamic model has a number of desirable properties, while maintaining all previous results from the Melitz (2003) model and full analytical tractability. Firstly, it integrates technological progress (vintage capital) and the displacement of varieties through competitive pressures from new entrants into the workhorse model of heterogeneous firms trade. Secondly, it generalizes the Melitz (2003) model to mirror traditional Solow model longrun growth properties, albeit including a more complex industry structure. Thirdly, exit and death of firms are endogenous and not depending on an 
exogenous death probability, whereby the resulting cross-sectional and dynamic predictions for market exit and firm closure of the extended model reflect empirical stylized facts on firm exit and closure. For example, in our model firms with a higher productivity draw will live longer. Similarly, in the model firm entry size on a market predicts survival, and firms exit markets after their market shares have shrunk beyond break-even. Thus, central empirical patterns are replicated. Furthermore, we find that trade liberalization still promotes intra-industry reallocations, but these reallocations now work through the direct effects of tougher thresholds and through a channel of firm survival, namely, more productive firms live longer than their less productive counterparts.

The remainder of the paper is structured as follows. Section 2 describes the continuous time dynamic extension of the symmetric n-country Melitz (2003) model including a detailed description of how we implement technological progress. Section 3 presents the results and the properties of the balanced growth path and we conduct static comparative analysis with respect to trade costs and the speed of technological progress. Section 4 compares our generalization of the Melitz (2003) model to the original model. Section 5 concludes.

\section{The Model}

In this section, we present a continuous time-dynamic extension of the symmetric n-country Melitz (2003) model. The extension is the introduction of exogenous technological progress through a vintage mechanism. To highlight the link between endogenous exit and technological progress, the model is kept as close a possible to the model in Melitz (2003) in all other dimensions. We operate throughout with the well-established Melitz (2003) notation and conventions and in line with much of the literature on heterogeneous firms in international trade from recent years we assume that productivity draws are Pareto-distributed (see e.g. Helpman et al., 2004; Chaney, 2008, and Eaton et al., forthcoming). Also in line with the literature on heterogeneous firms in international trade following Melitz (2003), we restrict attention to situations with a stable macro-environment for the firms. ${ }^{5}$ The inclusion of economy-wide technological progress implies of cause that a stable macroenvironment in our setting is formulated in terms of stable growth rates, i.e. we consider balanced growth paths.

\footnotetext{
${ }^{5}$ A few papers (including Burstein and Melitz, 2011; Atkeson and Burstein, 2010; Costantini and Melitz, 2009; Ruhl, 2008; Alessandria and Choi, 2011; Ghironi and Melitz, 2005) analyse numerically transitions between steady states.
} 


\section{$2.1 \quad$ Households}

The representative household supplies exogenously $L$ units of labor and chooses a consumption path $\left\{C_{s}\right\}_{s=t}^{\infty}$ to maximize utility

$$
U_{t}=\int_{t}^{\infty} \ln \left(C_{s}\right) d s
$$

subject to the budget constraint

$$
\dot{A}_{t}=i_{t} A_{t}+\Pi_{t}+L-R_{t},
$$

where $R_{t}=P_{t} C_{t}$ is expenditures, $P_{t}$ is the price index (to be defined below), $A_{t}$ is wealth, $i_{t}$ is the nominal interest rate, $\Pi_{t}$ is aggregate profits of domestic firms, and $L$ is labor income as wages are normalized to unity. We derive the Euler equation

$$
\frac{\dot{R}_{t}}{R_{t}}=i_{t}
$$

via standard intertemporal optimization techniques.

On a balanced growth path all variables grow at constant rates which cf. the Euler equation (3) implies that the interst rate is constant. From the budget constraint (2) and the constant interest rate it follows that a constant growth rate of wealth requires $R_{t}=\Pi_{t}+L$. For this condition to hold jointly with constant growth rates of aggregate profits and expenditures, it has to be the case that $\dot{\Pi}_{t}=\dot{R}_{t}=0$. This in turn implies that $i_{t}=\dot{A}_{t}=0$. Hence, on the balanced growth path wealth and expenditures are constant and the interest rate is zero; while consumption and the price level will change over time. ${ }^{6}$ Accordingly, we drop time subscripts where appropriate.

Expenditures, $R$, at any point in time are spread over the set of available varieties, $\Omega_{t}$, to maximize $C_{t}=\left[\int_{\omega \in \Omega_{t}}\left[c_{t}(\omega)\right]^{\frac{\sigma-1}{\sigma}} d \omega\right]^{\frac{\sigma}{\sigma-1}}$ implying a demand for each variety of

$$
c_{t}(\omega)=\frac{R}{P_{t}}\left(\frac{p_{t}(\omega)}{P_{t}}\right)^{-\sigma} \text { for all } \omega \in \Omega_{t},
$$

where $p_{t}(\omega)$ is the price of variety $\omega$ and

$$
P_{t}=\left[\int_{\omega \in \Omega_{t}}\left[p_{t}(\omega)\right]^{1-\sigma} d \omega\right]^{\frac{1}{1-\sigma}}
$$

is the price index.

\footnotetext{
${ }^{6} \mathrm{~A}$ positive interest rate would ensue if we had a positive discount rate, yet here we follow Melitz (2003) by assuming zero time discounting implying a zero interest rate to avoid the complexities from keeping track of the return to firms' sunk entry costs.
} 


\section{$2.2 \quad$ Firms}

Firms operate in a monopolistic competition setting with labor as the only input factor. They each produce a unique differentiated variety of a single final good. At entry each firm pays sunk innovation costs of $f_{e}$ labor units to innovate a unique variety and obtain a firm-specific constant and time-invariant marginal productivity $\varphi(\omega)$ drawn from a known time-varying distribution (elaborated below). The firm's labor requirement conditional on production is $l_{t}(\omega)=f+\frac{q_{t}(\omega)}{\varphi(\omega)}$, where $f$ is fixed production costs and $q_{t}(\omega)$ is output. ${ }^{7} \mathrm{~A}$ firm has to pay fixed costs of $f_{x}$ labor units for each of the $n$ export markets it chooses to serve, and moreover exports are subject to iceberg trade costs, $\tau \geq 1$. Upon entry and subsequently at each point in time, firms decide conditional on productivity and the current industry structure which markets to serve.

Given the constant elasticity of demand, prices are set as a constant markup, $\frac{\sigma}{\sigma-1}$, on marginal costs. Flow profits at time $t$ on the domestic market and on export markets for a firm with productivity $\varphi(\omega)$ can by use of (4) be written as

$$
\begin{aligned}
\pi_{t}(\varphi(\omega)) & =B_{t}(\varphi(\omega))^{\sigma-1}-f \\
\pi_{t}^{x}(\varphi(\omega)) & =B_{t} \tau^{1-\sigma}(\varphi(\omega))^{\sigma-1}-f_{x}
\end{aligned}
$$

where $B_{t}=\frac{1}{\sigma-1}\left(\frac{\sigma}{\sigma-1}\right)^{-\sigma} R P_{t}^{\sigma-1}$ is the firms endogenously determined market-specific demand component at time $t$. Profits in each market increase with marginal productivity $\varphi$ and due to the fixed costs only sufficienly productive firms are active. We define the exit and export threshold, $\varphi_{t}^{\text {exit }}$ and $\varphi_{t}^{x}$, by $\pi_{t}\left(\varphi_{t}^{\text {exit }}\right)=0$ and $\pi_{t}^{x}\left(\varphi_{t}^{x}\right)=0$, respectively. For the model to be consistent with the stylized fact that firms partition into exporters and nonexporters, we impose in line with the literature the parameter restriction $f_{x} \tau^{\sigma-1}>f$, which ensures that $\varphi_{t}^{x}>\varphi_{t}^{\text {exit }}$. Hence, firms partition such that firms with $\varphi>\varphi_{t}^{x}$ serve both the domestic and export markets, firms with $\varphi_{t}^{\text {exit }}<\varphi<\varphi_{t}^{x}$ serve only the domestic market whereas firms with $\varphi<\varphi_{t}^{\text {exit }}$ will not produce at all. From (6) and (7) it follows that $\varphi_{t}^{\text {exit }}=\left(\frac{f}{B_{t}}\right)^{\frac{1}{\sigma-1}}$ and that $\varphi_{t}^{x}=\left(\frac{f_{x} \tau^{\sigma-1}}{f}\right)^{\frac{1}{\sigma-1}} \varphi_{t}^{e x i t}$.

\footnotetext{
${ }^{7}$ In the present setting with CES preferences, fixed production costs are necessary to generate endogenous exit, in contrast, sunk cost alone would not generate endogenous exit.
} 


\subsection{Technological Progress}

We introduce technological progress as exogenous and continuous, thus following Dasgupta and Stiglitz's (1981) work on the dynamics of oligopolistic industries and innovation. In particular, we introduce exogenous and continuous improvements in the distribution of productivities available to entering firms. The central implication of continuously improving productivity draws - vintage capital - among new entrants paired with constant firm-specific productivities is that incumbent firms experience declining relative productivity over time and thus falling market shares over time, i.e. they face a competency trap. Eventually individual market shares decline to levels, such that firms cannot cover fixed production costs and endogenously shut down.

At entry a firm draws its firm-specific marginal productivity $\varphi$ that it maintains throughout its endogenous life. In this respect firms are still similar to firms in the original Melitz (2003) model, where firms with a fairly bad but viable $\varphi$ draw choose to produce (until hit by the random death shock), despite the fact that they observe many higher productivity firms with better technologies that coexist in the same industry, i.e. heterogeneity persists across firms and time. Due to selection, the average productivity of the incumbents of today will despite the improving technology be higher than the average productivity draw of tomorrow, i.e. at any point in time some of the drawn blue-prints are not worth bringing to the market.

Turning to the specifics, a firm entering the market at time $t$ of type $\omega$ has productivity $\varphi_{t}(\omega)$ which is a realization from the Pareto

$$
G_{t}\left(\varphi_{t}(\omega)\right)=1-\left(\frac{\varphi_{t}(\omega)}{\bar{\varphi}_{t}}\right)^{-k} \text { for } \varphi_{t}(\omega) \geq \bar{\varphi}_{t}
$$

where $\bar{\varphi}_{t}$ determines the location of the distribution and $k$ determines the shape of the distribution. The location parameter of the distribution improves exogenously and continuously at rate $\beta>0$, i.e. $\bar{\varphi}_{t}=e^{\beta t}$. Hence, the entire distribution of marginal productivities of entering firms moves rightwards at rate $\beta>0$ and thus first-order stochastically dominates the distribution of yesterday.

It is useful to decompose each productivity draw into a general and deterministic increasing state of technology component $\bar{\varphi}_{t}=e^{\beta t}$ (i.e. the vintage technology) and a stochastic firm-specific lottery component $\varphi_{0}(\omega, t)=$ $\varphi_{0}(\omega)=\frac{\varphi_{t}(\omega)}{\bar{\varphi}_{t}}$ such that we can write productivity draws at any time $t$ as

$$
\varphi_{t}(\omega)=\varphi_{0}(\omega) \bar{\varphi}_{t}=\varphi_{0}(\omega) e^{\beta t}
$$

where $\varphi_{0}(\omega)$ is a draw from a Pareto, $G_{0}$, with shape parameter $k$ and 
location parameter 1 . To see this note that

$$
\begin{aligned}
\operatorname{Pr}\left(\varphi_{0}(\omega) e^{\beta t}<x\right) & =\operatorname{Pr}\left(\varphi_{0}(\omega)<x e^{-\beta t}\right) \\
& =1-\left(x e^{-\beta t}\right)^{-k}=1-\left(\frac{x}{e^{\beta t}}\right)^{-k} \\
& =1-\left(\frac{x}{\bar{\varphi}_{t}}\right)^{-k}=\operatorname{Pr}\left(\varphi_{t}(\omega)<x\right) .
\end{aligned}
$$

Hence, at time $t$ the productivity of a firm of age $m$ and lottery component $\varphi_{0}(\omega)$ reads $\varphi_{0}(\omega) e^{\beta(t-m)}$. We surpress $\omega$ in the following to ease notation.

We obtain with the above assumptions tractability and analytical convenience, yet, these benefits come at the cost of generality. The specific modelling of technological progress and in particular the Pareto distribution ensure existence of a closed form balanced growth path with a stable industry structure. ${ }^{8}$ The key to this surprising tractability of our extension is that the Pareto distribution has the convenient property that the productivity distribution of firms from a given cohort that at any point in time have survived the increasingly tough selection, continues to be Pareto with shape parameter $k$ - only the location parameter increases over time. ${ }^{9}$ Moreover, the continuously increasing exit threshold (the location parameter) is common across cohorts, i.e. the decision to shut down is not so much determined by firm age, but by its productivity relative to the current industry structure. This is so since firm-specific productivity is the only firm characteristic that matters for current and future profitability cf. (6) and (7). Thus it follows that the productivity distribution among active firms is the same across various cohorts (see Lemma 3 below).

\section{Results}

Flow profits at time $t$ on the domestic market and on export markets for a firm of age $m$ with lottery component $\varphi_{0}$ are given by

$$
\begin{aligned}
& \pi_{t, m}\left(\varphi_{0}\right)=B_{t} e^{\beta(\sigma-1)(t-m)} \varphi_{0}^{\sigma-1}-f \\
& \pi_{t, m}^{x}\left(\varphi_{0}\right)=B_{t} \tau^{1-\sigma} e^{\beta(\sigma-1)(t-m)} \varphi_{0}^{\sigma-1}-f_{x}
\end{aligned}
$$

\footnotetext{
${ }^{8}$ In fact the specific formulation of technological progress implies that the $j^{\prime}$ 'th uncentered moment, $E\left(\varphi_{t}^{j}\right)=\frac{k}{k-j} \bar{\varphi}_{t}^{j}$, grows at rate $\beta j$ which in turn implies that the coefficient of variation $\left(=\sqrt{\frac{1}{k(k-2)}}\right)$ is time-invariant.

${ }^{9}$ With alternative distributional assumptions we have to rely on simulation results and are unable to deliver analytical solutions. The Pareto distribution has found ample application as well as empirical support in the heterogeneous firms literature.
} 
In the Appendix we show that the balanced growth path has the property that $\dot{B}_{t}=-\beta(\sigma-1) B_{t}$. Intuitively a balanced growth path with a stable industry structure requires stable exit and export lottery thresholds, which in turn requires the above flow profits to be time-invariant. This can only be achieved if the market-specific demand component $B$ decreases to balance the technological improvement, i.e. $B$ must decrease at rate $\beta(\sigma-1) .{ }^{10}$ Writing $B_{t}=B_{0} e^{-\beta(\sigma-1) t}$ the flow profit expressions can be rewritten as

$$
\begin{aligned}
& \pi_{t, m}\left(\varphi_{0}\right)=\pi_{m}\left(\varphi_{0}\right)=B_{0} e^{-\beta(\sigma-1) m} \varphi_{0}^{\sigma-1}-f \\
& \pi_{t, m}^{x}\left(\varphi_{0}\right)=\pi_{m}^{x}\left(\varphi_{0}\right)=B_{0} \tau^{1-\sigma} e^{-\beta(\sigma-1) m} \varphi_{0}^{\sigma-1}-f_{x},
\end{aligned}
$$

where the profit flows only depend on the firm's age and its lottery component.

\subsection{Endogenous Exit}

Due to the exogenous technological progress, a firm observes that its productivity falls over time relative to younger competitors. Eventually, the market share will fall to a level where the firm is unable to cover fixed costs in a given market, and the firm therefore endogenously exits the market at that point in time. The ages at which a firm shuts down $\left(m^{\text {exit }}\right)$ or leaves a given export market $\left(m^{x}\right)$ are determined by

$$
\begin{gathered}
\pi_{m^{e x i t}}\left(\varphi_{0}\right)=0 \Leftrightarrow m^{e x i t}\left(\varphi_{0}\right)=\max \left\{0, \ln \left(\frac{B_{0} \varphi_{0}^{\sigma-1}}{f}\right)^{\frac{1}{\beta(\sigma-1)}}\right\} \\
\pi_{m^{x}}\left(\varphi_{0}\right)=0 \Leftrightarrow m^{x}\left(\varphi_{0}\right)=\max \left\{0, \ln \left(\frac{B_{0} \varphi_{0}^{\sigma-1}}{f_{x} \tau^{\sigma-1}}\right)^{\frac{1}{\beta(\sigma-1)}}\right\}
\end{gathered}
$$

Note that only firms with sufficiently high lottery components have been active in a given market to begin with. Define the exit and export lottery thresholds by

$$
\begin{aligned}
m^{\text {exit }}\left(\varphi_{0}^{\text {exit }}\right) & =0 \Leftrightarrow \varphi_{0}^{\text {exit }}=\left(\frac{f}{B_{0}}\right)^{\frac{1}{\sigma-1}} \\
m^{x}\left(\varphi_{0}^{x}\right) & =0 \Leftrightarrow \varphi_{0}^{x}=\left(\frac{f_{x} \tau^{\sigma-1}}{B_{0}}\right)^{\frac{1}{\sigma-1}}
\end{aligned}
$$

\footnotetext{
${ }^{10}$ The stable industry structure implies that the distribution of marginal productivities increases at rate $\beta$ which in turn implies that prices decrease at rate $\beta$. The time-invariant nominal expenditures and time-invariant fixed and sunk costs imply, given the constant mark-ups, a time-invariant number of varieties, $M_{t}$. Thus it follows that $B_{t}=\frac{1}{\sigma-1}\left(\frac{\sigma}{\sigma-1}\right)^{-\sigma} R P_{t}^{\sigma-1}$ decreases at rate $\beta(\sigma-1)$. See the Appendix for further details.
} 
implying that only firms with $\varphi_{0} \geq \varphi_{0}^{\text {exit }}$ ever produce and only firms with $\varphi_{0} \geq \varphi_{0}^{x}$ ever exports.

Lemma 1. Conditional on firm-specific productivity, firm death is endogenous and deterministic.

Proof. Follows directly from (14)

Proposition 1. More productive firms survive longer. Entry size of firms on a given market is positively linked to the duration of serving this market.

Proof. The effect of productivity on firm survival follows by inspection of (6), noting that more productive firms have a higher $\varphi$, taking into account that $B_{t}$ decreases at rate $\beta(\sigma-1)$, and recalling that exit occurs when flow profits equal zero. The second statement follows from (14) and (15), noting that initial sales (size) are determined by the lottery component $\varphi_{0}$, in particular, initial domestic sales equal $R P_{t}^{\sigma-1}\left(p_{t}\left(\varphi_{t}\right)\right)^{1-\sigma}=$ $\sigma B_{t}\left(\varphi_{t}\right)^{\sigma-1}=\sigma B_{0} e^{-\beta(\sigma-1) t}\left(\varphi_{0} e^{\beta t}\right)^{\sigma-1}=\sigma B_{0}\left(\varphi_{0}\right)^{\sigma-1}$ and initial export sales equal $n \sigma B_{0}\left(\varphi_{0} \tau^{-1}\right)^{\sigma-1}$.

Corollary 1. Exporters survive longer than non-exporters

Proof. Follows from Proposition 1 as exporters are more productive than non-exporters per their initial selection into the export market.

We note in passing that it would be straightforward also to include an additional exogenous death probability $\delta$ - as in the original Melitz (2003) model - into our framework. Then one would observe additional exit/death among both exporters and non-exporters, but the expected lifetime is longer for more productive firms (and exporters).

\subsection{Free Entry and Thresholds in Equilibrium}

Taking the endogenous lifetime of firms into account, the net present value ${ }^{11}$ of lifetime profits on the domestic and on each export market conditional on the lottery draw read

$$
\begin{aligned}
\pi\left(\varphi_{0}\right) & =\int_{0}^{m^{e x i t}\left(\varphi_{0}\right)} \pi_{s}\left(\varphi_{0}\right) d s=\int_{0}^{m^{e x i t}\left(\varphi_{0}\right)}\left(B_{0} e^{-\beta(\sigma-1) s} \varphi_{0}^{\sigma-1}-f\right) d s \\
\pi^{x}\left(\varphi_{0}\right) & =\int_{0}^{m^{x}\left(\varphi_{0}\right)} \pi_{s}^{x}\left(\varphi_{0}\right) d s=\int_{0}^{m^{x}\left(\varphi_{0}\right)}\left(B_{0} \tau^{1-\sigma} e^{-\beta(\sigma-1) s} \varphi_{0}^{\sigma-1}-f_{x}\right) d s .
\end{aligned}
$$

\footnotetext{
${ }^{11}$ As argued above the interest rate on the balanced growth path equals the subjective discount rate which is assumed to be zero.
} 
There is free entry into the industry and thus firms enter until expected net present value of profits prior to realization of the productivity/lottery draw equals the sunk entry costs, $f_{e}$, i.e. the free entry condition reads

$$
\int_{\varphi_{0}^{\text {exit }}}^{\infty} \pi\left(\varphi_{0}\right) d G_{0}\left(\varphi_{0}\right)+\int_{\varphi_{0}^{x}}^{\infty} \pi^{x}\left(\varphi_{0}\right) d G_{0}\left(\varphi_{0}\right)=f_{e} .
$$

Free entry drives expected profits prior to entry to zero. Accordingly, at every point in time firms have no incentive to delay entry in order to take advantage of the improved future productivity distribution. This is in fact fully parallel to firm entry behavior in the original Melitz (2003) model, where firms do not discharge viable but below average productivity lottery draws in order to retake the lottery in hope of a better draw. It follows directly that our extension adds no additional insights on entry dynamics compared to the original.

The free entry condition (18) by use of (16) and (17) pins down the exit and export lottery thresholds in equilibrium

$$
\begin{aligned}
\varphi_{0}^{\text {exit }} & =\left(\frac{(\sigma-1)}{k-(\sigma-1)} \frac{f}{f_{e}} \frac{1}{\beta k}\right)^{\frac{1}{k}}\left(1+n \frac{f_{x}}{f}\left(\frac{f_{x} \tau^{\sigma-1}}{f}\right)^{-\frac{k}{\sigma-1}}\right)^{\frac{1}{k}} \\
\varphi_{0}^{x} & =\left(\frac{f_{x} \tau^{\sigma-1}}{f}\right)^{\frac{1}{\sigma-1}} \varphi_{0}^{\text {exit }}
\end{aligned}
$$

\subsection{Industry Structure on the Balanced Growth Path}

This section analyzes the industry structure on the balanced growth path.

\section{Aggregate variables}

The time-invariant lottery thresholds (19) and (20) and time-invariant labor supply implies (as shown in the Appendix) a time-invariant mass of firms given by

$$
M=\frac{M^{e}\left(\varphi_{0}^{e x i t}\right)^{-k}}{\beta k}
$$

where

$$
M^{e}=\frac{\sigma-1}{\sigma} \frac{1}{k} \frac{L}{f_{e}}
$$

is the time-invariant mass of firms entering the industry (with or without success) at any point in time. Using (21) and (22), the lottery tresholds (19) 
and (20), constant mark-up pricing and the productivity distributions (8) we can now express the price index (5) as

$$
P_{t}=\frac{\sigma}{\sigma-1}\left(\frac{L}{\sigma f}\right)^{\frac{1}{1-\sigma}} \frac{e^{-\beta t}}{\varphi_{0}^{e x i t}} .
$$

Lemma 2. Technological progress feeds into the price index. The price index decreases at rate $\beta$, while consumption grows at rate $\beta$.

Proof. Follows directly from (23) and the fact that we have constant nominal expenditure.

\section{Productivity distribution}

We first consider the productivity distribution of all active firms. The mass of firms at time $t$ with productivity above the level $\hat{\varphi} \geq \varphi_{t}^{\text {exit }}$ consists of the sum (integral) of masses of firms from various cohorts with productivity above $\hat{\varphi}$ and can thus be written

$$
M_{\varphi>\hat{\varphi}}=\int_{0}^{\infty} M^{e}\left(1-G_{t-m}(\hat{\varphi})\right) d m=M^{e}\left(\frac{\hat{\varphi}}{\bar{\varphi}_{t}}\right)^{-k} \frac{1}{\beta k} .
$$

Accordingly, the fraction of active firms with a productivity level below $\hat{\varphi}$ at time $t$ is

$$
H_{t}(\hat{\varphi})=\frac{M_{\varphi>\varphi_{t}^{e x i t}}-M_{\varphi>\hat{\varphi}}}{M_{\varphi>\varphi_{t}^{e x i t}}}=1-\left(\frac{\hat{\varphi}}{\varphi_{t}^{\text {exit }}}\right)^{-k} \text { for } \hat{\varphi}>\varphi_{t}^{\text {exit }} .
$$

It follows, that at any point in time the distribution of marginal productivities among active firms is Pareto with shape parameter $k$ and location parameter $\varphi_{t}^{\text {exit }}$

Lemma 3. The distribution of marginal productivities, $\varphi$, among active firms at time $t$ is Pareto with shape parameter $k$ and location parameter $\varphi_{t}^{\text {exit }}$ that increases at rate $\beta$.

Corollary 2. The distribution of marginal productivity at time $t$ first-order stochastic dominates that at time $t-j$ for all $j>0$.

Moreover, the distribution of marginal productivity is identical for all cohorts. To see this, consider the productivity distribution of active firms of a given cohort of age $m$ at time $t$

$H_{t, m}(\hat{\varphi})=\frac{M^{e}\left(1-G_{t-m}\left(\varphi_{t}^{e x i t}\right)\right)-M^{e}\left(1-G_{t-m}(\hat{\varphi})\right)}{M^{e}\left(1-G_{t-m}\left(\varphi_{t}^{e x i t}\right)\right)}=1-\left(\frac{\hat{\varphi}}{\varphi_{t}^{\text {exit }}}\right)^{-k}$ for $\hat{\varphi}>\varphi_{t}^{\text {exit }}$ 
The productivity distribution is Pareto with shape parameter $k$ and location parameter $\varphi_{t}^{\text {exit }}$ and does not depend on the age of the cohort, i.e. the productivity distribution among active firms (that is firms still alive) is the same for each cohort.

\section{Age distribution}

Turning to the age distribution, we have that the mass of firms of age $m$ is given by $M_{m}=M^{e}\left(1-G_{t-m}\left(\varphi_{t}^{\text {exit }}\right)\right)$ and the density of firms of age $m$ accordingly reads

$$
b(m)=\frac{M^{e}\left(1-G_{t-m}\left(\varphi_{t}^{e x i t}\right)\right)}{M}=\beta k e^{-\beta k m} \text { for } m \geq 0
$$

Lemma 4. The age distribution of firms is exponential with parameter $\beta k$ and the average age of active firms and the expected lifetime conditional on sucesfull entry is $\frac{1}{\beta k}$.

Proof. Follows directly from (25) and that $\int_{0}^{\infty} b(m) m d m=\frac{1}{\beta k}$

Faster technological progress (higher $\beta$ ) reduces expected lifetime as competition from younger cohorts is tougher. Less dispersion in the productivity distribution (higher $k$ ) reduces expected lifetime as it reduces the chance of drawing a high lottery component and accordingly reduces the chances of staying in the market for a long time.

If we split the population of firms into current exporters and current nonexporters, we similarly find that the age distribution among each group is exponential with parameter $\beta k .{ }^{12}$ However, it is more illustrative to split the population of firms into those never exporting and those exporting at some

\footnotetext{
${ }^{12}$ To see this, note that the mass of exporters of age $m$ is given by $M_{m}^{x}=$ $M^{e}\left(1-G_{t-m}\left(\varphi_{t}^{x}\right)\right)$ and the mass of pure domestic firms of age $m$ is given by $M_{m}^{d}=$ $M^{e}\left(G_{t-m}\left(\varphi_{t}^{x}\right)-G_{t-m}\left(\varphi_{t}^{e x i t}\right)\right)$. Thus, we have
}

$$
\begin{aligned}
b^{x}(m) & =\frac{M_{m}^{x}}{M^{x}}=\frac{M^{e}\left(1-G_{t-m}\left(\varphi_{t}^{x}\right)\right)}{\int_{0}^{\infty} M^{e}\left(1-G_{t-m}\left(\varphi_{t}^{x}\right)\right) d m}=\beta k e^{-\beta k m} \\
b^{d}(m) & =\frac{M_{m}^{d}}{M}=\frac{M^{e}\left(G_{t-m}\left(\varphi_{t}^{x}\right)-G_{t-m}\left(\varphi_{t}^{\text {exit }}\right)\right)}{\int_{0}^{\infty} M^{e}\left(G_{t-m}\left(\varphi_{t}^{x}\right)-G_{t-m}\left(\varphi_{t}^{\text {exit }}\right)\right) d m}=\beta k e^{-\beta k m}
\end{aligned}
$$


point during their lives. We have

$$
\begin{aligned}
E\left(m^{\text {exit }} \mid \varphi_{0} \geq \varphi_{0}^{\text {exp ort }}\right) & =\frac{1}{\beta k}\left(1+\ln \left[\frac{f_{x}}{f}\right]^{\frac{k}{\sigma-1}}+k \ln \tau\right) \\
E\left(m^{\text {exit }} \mid \varphi_{0}^{\text {exit }} \leq \varphi_{0} \leq \varphi_{0}^{\text {exp ort }}\right) & =\frac{1}{\beta k}\left(1-\frac{\left.\ln \left[\left(\frac{f_{x} \tau^{\sigma-1}}{f}\right)^{\frac{k}{\sigma-1}}\right]\right)}{\left(\frac{f_{x} \tau^{\sigma-1}}{f}\right)^{\frac{k}{\sigma-1}}-1}\right) .
\end{aligned}
$$

It follows that:

Proposition 2. Trade liberalization decreases the expected lifetime of exporters and non-exporters, yet the expected lifetime of all firms - conditional on starting production - is unaffected.

Proof. The first part follows directly from the partial derivatives of (26) and (27) wrt $\tau$. The second part follows from Lemma 4.

Lifetime is deterministic conditional on the lottery component $\varphi_{0} \mathrm{cf}$. (14) and exporting firms survive longer due to the tougher selection into export markets. The effect of trade liberalization works through industry dynamics and in particular the selection mechanism. As trade is liberalized, the selection into the export market is not as tough and accordingly average/expected lifetime among exporters declines, i.e. after liberalization less productive firms (which accordingly will be out-competed earlier) engage in exports. Turning to the non-exporters, we have the flip-side of the coin, namely that those becoming exporters are the previous most productive and thus longest living non-exporters. Hence the less strict selection into the export market - subsequent to liberalization - also reduces the average lifetime of non-exporters. The average lifetime of those firms that actually choose to start production remains, however, unaffected by trade liberalization. This happens, because the lifetime reduction for the group of exporters and non-exporters is counterbalanced by the shift of firms from non-exporter status to exporter status. Trade liberalization increases the share of exporters among the active firms; and exporters will always survive longer than non-exporters.

\section{Properties of exiting firms}

What are the characteristics of exiting firms in the extended model? The exponential age distribution and the fact that the productivity distribution among active firms is the same across cohorts have some straightforward (and empirically relevant) implications for the composition of exit waves. 
Corollary 3. For a given exit wave, younger (older) age cohorts account for a larger (smaller) share of the exiting firms.

Obviously, this result hinges on our assumption of Pareto distributed productivities.

Next we note that the market shares of a firm with productivity $\varphi$ on the domestic and export markets are

$$
\begin{aligned}
& s_{t}(\varphi)=\frac{\frac{R}{P_{t}}\left(\frac{p(\varphi)}{P_{t}}\right)^{-\sigma} p(\varphi)}{R}=\left(\frac{\sigma}{\sigma-1}\right)^{1-\sigma} \varphi^{\sigma-1} P_{t}^{\sigma-1} \\
& s_{t}^{x}(\varphi)=\left(\frac{\sigma}{\sigma-1}\right)^{1-\sigma} \tau^{1-\sigma} \varphi^{\sigma-1} P_{t}^{\sigma-1}
\end{aligned}
$$

Combining (6), (7), (28) and (29), we find that $\pi_{t}(\varphi)=\frac{s_{t}(\varphi) R}{\sigma}-f$ and $\pi_{t}^{x}(\varphi)=\frac{s_{t}^{x}(\varphi) R}{\sigma}-f_{x}$. Accordingly, flow profits increase in the market shares and exiting firms will thus be small (have a small market share). Market shares decline over time due to a decreasing price level, $P_{t}$ (see (23)), and exiters thus observe periods of declining market shares prior to exit. ${ }^{13}$ Furthermore, exporters that cease their exporting activity do not shut down on their respective home markets, since $\phi_{t}^{x}>\phi_{t}^{\text {exit }}$, c.f. (19) and (20).

Corollary 4. Only small firms exit markets. Firms observe a declining market share before market exit and firm closure. Exporters that cease to export continue to exist as pure domestic firms until they shut down completely. The absolute output volume of an exiting firm that exits at time $t$ is larger than that of a firm that exits at time $t-j$ for all $j>0$.

These results (Corollaries 3 and 4) correspond to the stylized facts of export market exit and firm death that have been derived in the empirical literature based on firm-level data (see the introduction).

\section{Growth Properties and Productivity}

Turning to the growth properties of the model, we have that real GDP (per capita) grows on the balanced growth path at rate $\beta$ which is the exogenous growth rate of the technology available to new firms. To see this recall from

\footnotetext{
${ }^{13}$ In fact firms shrink from birth onwards in our model. An assumption of an initial phase of firm-specific productivity growth in excess of $\beta$, followed by a period of below $\beta$ productivity growth (say after some exogenous random shock), would obviously generate richer patterns of firm size (and relative productivity) developments; albeit it is unlikely to bring about analytical tractable solutions.
} 
the problem of the household that nominal expenditures are constant on the balanced growth path whereas the price level (23) decreases at rate $\beta$. In this sense the balanced growth path mimics that of, for example, the traditional Solow or Ramsey model with exogenous technological progress. The main difference is that our model is a vintage model with a much richer industry structure.

Turning to productivity and productivity growth across firms, we distinguish between marginal productivity and observable productivity. Real life data does not represent marginal productivity. Accordingly, empirical studies consider average but observable productivity measures such as value-added per employee, $\rho$, (see Schröder and Sørensen, 2011, for further discussion). In doing so one has to take proper account of nominal issues as the numerator is in nominal terms and the denominator is in real terms. This distinction becomes non-trivial in the dynamic extension presented here. To illustrate, we stop - for the moment - to use the wage as the model's nominal anchor. Then, for pure domestic and exporting firms of age $m$ at time $t$ the value-added per employee reads

$$
\begin{aligned}
\rho_{t}^{d}\left(\varphi_{t-m}(\omega)\right) & =\frac{p\left(\varphi_{t-m}(\omega)\right) \frac{R}{P_{t}}\left(\frac{p\left(\varphi_{t-m}\right)}{P_{t}}\right)^{-\sigma}}{\frac{1}{\varphi_{t-m}} \frac{R}{P_{t}}\left(\frac{p\left(\varphi_{t-m}\right)}{P_{t}}\right)^{-\sigma}+f} \\
& =w_{t} \frac{\sigma B_{0}\left[\varphi_{0}(\omega) e^{-\beta m}\right]^{\sigma-1}}{(\sigma-1) B_{0}\left[\varphi_{0}(\omega) e^{-\beta m}\right]^{\sigma-1}+f} \\
\rho_{t}^{x}\left(\varphi_{t-m}(\omega)\right) & =w_{t} \frac{\left(1+n \tau^{1-\sigma}\right) \sigma B_{0}\left[\varphi_{0}(\omega) e^{-\beta m}\right]^{\sigma-1}}{\left(1+n \tau^{1-\sigma}\right)(\sigma-1) B_{0}\left[\varphi_{0}(\omega) e^{-\beta m}\right]^{\sigma-1}+f+n f_{x}^{(31)}}
\end{aligned}
$$

Since the age distribution and the exit and export lottery thresholds are time-invariant on the balanced growth path, it follows that the distribution of observable productivity distribution across firms only changes due to changes in the nominal wage.

Proposition 3. Average marginal productivity across firms grows at rate $\beta$. Average observable productivity grows at rate $\beta$ plus the inflation level $\left(\frac{\dot{P}_{t}}{P_{t}}\right)$ when measuring value-added per employee in nominal terms. Average observable productivity grows at rate $\beta$, when measuring value-added per employee in real terms.

Proof. The first part follows directly from the productivity distribution among active firms (24). The results concerning observable productivity 
follow from $(30),(31)$ and that the real wage equals $\frac{w_{t}}{P_{t}}$. In the setting above the wage is chosen as the nominal anchor implying that $w_{t}=1$ for all $t$ and the real wage increases at rate $\beta$ as the price level decreases at rate $\beta$. However, we could have chosen other nominal anchors.

Analyzing the effects of the speed of technological progress, we find that

Proposition 4. A higher growth rate in technological progress shortens the average time a firm survives in any market and softens selection (pushing the exit cut-off threshold down).

Proof. Shortened average time in any market follows from $E\left(m^{\text {exit }} \mid \varphi_{0} \geq \varphi_{0}^{\text {exit }}\right)=\frac{1}{\beta k}$ and $E\left(m^{x} \mid \varphi_{0} \geq \varphi_{0}^{x}\right)=\frac{1}{\beta k}$ and the softer selection follows from the partial derivative of the exit lottery threshold $\varphi_{0}^{\text {exit }}$ wrt. $\beta$, see equation (19).

Faster technological progress ceteris paribus reduces the value of entering the industry since firms will loose market shares faster. With fewer firms joining the lottery, the cut-off thresholds become less strict. Note, that this result highlights a potential trade-off between short-run average productivity and the growth rate. Even though a higher $\beta$ increases growth at the balanced growth path, it also softens selection and thus tends to reduce average productivity in the short run. However, to address such dynamic effects in more depth an analysis of the transition path between the balanced growth paths would be needed.

Turning to the effect of trade liberalization on selection we find:

Proposition 5. Trade liberalization makes selection harder (pushing the exit cut-off threshold up).

Proof. Follows directly from the partial derivative of the exit lottery threshold $\varphi_{0}^{\text {exit }}$ wrt. $\tau$.

Hence, trade liberalization has a level effect on output but no effect on sustained growth in this extended Melitz (2003) framework.

\section{Contributions and Comparison to Melitz (2003)}

Readers familiar with the Melitz (2003) model (in particular under the assumption of Pareto distributed productivities) will by now have realized that all the novel predictions of the Melitz (2003) model apply in this extended 
version. Moreover, it should be clear at this point that the inclusion of exogenous technological progress has not increased the analytical complexity significantly. We have throughout been able to deliver closed form solutions. Hence, abandoning the random firm death probability $\delta$ comes at zero costs in terms of generality and little cost in terms of complexity relative to a Melitz (2003) model with Pareto distributed productivities. This section shortly relates the predictions of the present model with those of the Melitz (2003) model and emphasizes similarities and differences as well as the limitations of the current model and issues for future research.

The extension of the Melitz (2003) model made by the introduction of economy-wide exogenous technological improvement through a vintage mechanism contributes in a number of areas. Obviously, the extension fleshes out some technological progress and competition mechanisms and provides some growth implications. Furthermore, our model also has some new implications for the industry structure and time dynamics which are at the core within the literature on heterogeneous firms in international trade, and lastly - and most centrally for the current paper - the extension has interesting implications for exit and firm death that bring the model better in line with stylized facts. We discuss these various areas in turn.

The introduction of exogenous technological progress allows us to show how such progress - via a mechanism of creative destruction - displaces older varieties by newer varieties, this effect is not present in the original Melitz (2003) model.

Concerning the dynamics of the two models, we obviously find significant differences when it comes to growth. Only the extended model has growth in real GDP and average (real) productivity. However, the growth properties should not be seen as a contribution to the growth literature since the balanced growth path established simply mimics that of, for example, the traditional Solow model with exogenous technological progress. The only difference to a traditional Solow model is that our model is a vintage model with a much richer industry structure. However, in the trade context the inclusion of growth is novel. Despite the difference in growth properties between the original Melitz (2003) model and the current extension, both models share the properties of a constant mass of active firms and a constant mass of firms entering the industry.

The industry structures in the two models are very similar when comparing snap-shot pictures. The only exception is the group of exiting firms. Exiting firms are special in the extension since they shut down endogenously. They do so because they are relatively unproductive - much in the same fashion that firms start production in these models because they are relatively productive. Apart from this difference we find ample overlap. Looking at 
the productivity of active firms, we have shown that the productivity distribution for each cohort and thus for all firms is Pareto with shape parameter $k$ and scale parameter $\varphi^{\text {exit }}$ in both models, cf. Lemma 3, similar results follow for firm size. Furthermore, albeit not explicitly shown in the Melitz (2003) model, the age distributions of active firms (also if we split the population of firms into exporters and non-exporters) are exponential in both models. From the exit and export thresholds it also follows that the fractions of firms exporting and thus openness measures are identical in the two models. Thus, on many fundamentals the industry structures are very similar in the two models, yet there are a few important differences. First, the parameter of the age distribution equals $\beta k$ in the extended model and average firm duration conditional on starting production accordingly must decrease in the speed of technological progress and increase in the degree of firm heterogeneity, cf. Lemma 4. In the Melitz (2003) model the parameter of the exponential age distribution simply equals the exogenous death probability, $\delta$, and is thus invariant to the level of firm heterogeneity. Second, the exit threshold, $\varphi^{\text {exit }}$, in the extended model equals that of the Melitz (2003) model except that it is scaled by the factor $\bar{\varphi}_{t}\left(\frac{\delta}{\beta k}\right)^{k}$. Again we find that the speed of technological progress and the degree of firm heterogeneity have effects on the industry structure not found in the conventional Melitz (2003) framework. However, if $\beta=\frac{\delta}{k}$, the age distributions would be identical and for the same state of technology (same productivity distribution available to entering firms) also thresholds and thus productivity distributions would be identical in the two models, i.e. the Melitz (2003) model is in this respect a special case of the current extension. Hence, except from exit behavior it is fair to conclude that the cross-sectional properties of the industry structure are fairly similar.

A remark is in order concerning intra-industry reallocations. A key contribution of the Melitz (2003) model is the intra-industry reallocations in response to trade liberalization. The extended model has similar intra-industry reallocations when it comes to trade liberalization, see Proposition 5. In both models trade liberalization strengthens the selection mechanism into the market as the exit thresholds increases. This in turn reduces the price level and thus has a positive impact on welfare. In both models trade liberalization increases the level of welfare, but has no effects on steady-state (balanced growth path) growth. The only difference is that in the extended model high-productivity firms displace lower-productivity firms, partly also because they are longer-lived.

Finally, we can compare exit between the two models. The main difference between the predictions of the two models and thus the main contribution 
of this paper regards capturing some central stylized facts of firm exit. The technological progress in our extended model implies that firms eventually shut down endogenously whereas in the Melitz (2003) model active firms leave the market when hit by an exogenous death shock. ${ }^{14}$ From a theoretical point of view the endogenous exit behavior of firms in the extended model is more satisfying than an exogenous death shock and more in line with empirical evidence as it predicts that exiting firms are the worst performing with low and declining market shares, low (relative) productivities and low profits (see Proposition 1, Corollary 1 and Corollary 4). On the contrary - and out of line with empirical evidence - the Melitz (2003) model predicts that all active firms - irrespective of performance - are equally likely to exit. Hence, only the extended model captures the important fact that firms staying in the industry perform better than the group of exiting firms prior to their exit decision. As a consequence, the extended model predicts that more productive firms and more profitable firms will stay longer in the market (industry), cf. Proposition 1. These novel predictions derived from the extension are largely in line with the available empirical evidence.

In light of the above discussion, the extended Melitz (2003) model performs similar to the original and captures several additional items. However, there are also several shortcomings and a number of unresolved issues in the extended version. Firstly, and in fact a severe drawback compared to the original Melitz (2003) model, the extended model is only analytically solvable under an assumption of Pareto distributed productivities. Moreover, the solutions presented here depend on a very specific modeling of technological progress, i.e. a change in the location parameter of the Pareto distribution. Secondly, firms shrink from birth onwards. Obviously, this contradicts empirical patterns. An assumption where firms initially start with an individual technological growth rate in excess of the industry-wide progress until they (randomly) stop to innovate could create a more realistic patterns. However, it is unlikely that such an extension lends itself readily for analytical solutions. Thirdly, technological progress is exogenous, the model has little to add on the drivers of this progress. A promising ally for future research would be to introduce imitation, where new firms can imitate technologies from the pool of realized blueprints, such imitations would endogenously advance technology use in the economy, see Luttmer (2007) who compares exogenous technological progress with imitation-driven progress in a model with selection and growth. Fourthly, we have shown that in the current framework trade liberalization has only a level effect on output and no

\footnotetext{
${ }^{14}$ Exit per se is essential for this class of models to ensure a meaningful steady state equilibrium.
} 
permanent growth effects per se, even though it is ultimately an empirical question we would argue that future research - for example when looking into endogenous technological progress - must address the trade/growth link in more detail; see Impullitti and Licandro (2010) for a recent contribution in this direction. Finally, the current extension generates in fact further predictions that future empirical research could address. For example, real world industries will differ in their speed of technological progress and in their fixed costs of market access and production. Our model predicts lower exit rates for technologically slowly evolving industries (low $\beta$ ). We would argue, that the effects identified in the current paper are most likely to be observed in growing and technologically fast advancing sectors (e.g. IT or telecommunication), and less likely to matter in mature and consolidated sectors (e.g. auto-motive). Similarly, the predictions of trade liberalization on firm age and exit (Propositions 2 and 5) could in principle be taken to the data, examining the effect of trade liberalization episodes in further detail.

\section{Conclusion}

Firm exits from export markets and firm closures are prominent feature of modern international trade. The present paper develops an extension of the Melitz (2003) model to derive a simple, analytically solvable dynamic framework able to address exit. The single modification we evoke is the inclusion of exogenous technological progress through a vintage mechanism, such that newer firms draw from an improved productivity distribution and accordingly older firms will eventually be ousted from the market place. Thus, the paper highlights how competition forces are an important transmission channel between technological progress and firm exit dynamics and how they interact with opening to trade.

Our model extension is able to capture the stylized facts of export market exit and firm closure. Firstly, high productivity firms (at any point in time) are likely also to produce in the future, i.e. they survive longer. That is, we have now a positive link between relative productivity and firm survival and market presence, respectively. Secondly, entry size of firms on a given market is positively linked to the duration of serving this market. Thirdly, large exporters do not exit export markets, but smaller exporters do, i.e. firms exit markets after they have lost market shares, and exporters that cease to export will still serve their domestic market. Fourthly, opening to trade gives an economy-wide productive redistribution by toughening entry thresholds, and it reduces the expected lifetime of exporters as well as non-exporters, even at constant rates of technological progress. Finally, dampened technological 
progress affects economy-wide productivity directly, via smaller productivity improvements for new start-ups, and indirectly, via weaker selection and the longer survival of firms (i.e. inferior and older technologies stay longer in the market).

Apart from the theoretical and methodological value of generalizing the Melitz (2003) framework to include technological progress, growth and endogenous exit, the model extension has potentially further implications for empirical research. From an empirical perspective the two critical blackboxes in the new heterogeneous firms trade theory are obviously the birth of firms (the lottery) and the death of firms (random shock). By the very definition of firm-level data, empirical research has ample information and data recordings on firms prior to and during market exit or firm death; in contrast we have next to no information when it comes to the entrepreneurial birth of a firm. Hence, empirical research into the lottery is largely unguided by current trade theory, while research into the market exit and death of firms can at least get some new pointers from the extension of the Melitz (2003) framework presented here. 


\section{A Appendix: Derivation of the Balanced Growth Path}

\section{Industry structure}

On the balanced growth path $B$ grows at a constant rate, say $g_{B}$ for the moment. Flow profits at time $t$ on the domestic market and on export markets for a firm with lottery component $\varphi_{0}$ and age $m$ are thus given by

$$
\begin{aligned}
& \pi_{t, m}\left(\varphi_{0}\right)=B_{0} e^{g_{B} t} e^{\beta(\sigma-1)(t-m)} \varphi_{0}^{\sigma-1}-f \\
& \pi_{t, m}^{x}\left(\varphi_{0}\right)=B_{0} e^{g_{B} t} \tau^{1-\sigma} e^{\beta(\sigma-1)(t-m)} \varphi_{0}^{\sigma-1}-f_{x},
\end{aligned}
$$

The firm exits when domestic market profits reach zero, which occurs at age

$\pi_{t, m^{e x i t}}\left(\varphi_{0}\right)=0 \Leftrightarrow m^{\text {exit }}=\max \left\{0, t\left(1+\frac{g_{B}}{\beta(\sigma-1)}\right)+\ln \left(\frac{B_{0} \varphi_{0}^{\sigma-1}}{f}\right)^{\frac{1}{\beta(\sigma-1)}}\right\}$

and similarly exit export markets age age

$$
\pi_{t, m^{x}}\left(\varphi_{0}\right)=0 \Leftrightarrow m^{x}=\max \left\{0, t\left(1+\frac{g_{B}}{\beta(\sigma-1)}\right)+\ln \left(\frac{B_{0} \varphi_{0}^{\sigma-1}}{f_{x} \tau^{\sigma-1}}\right)^{\frac{1}{\beta(\sigma-1)}}\right\}
$$

Only firms with $m^{\text {exit }} \geq 0$ becomes active and $m^{\text {exit }}\left(\varphi_{0}^{\text {exit }}\right)=0 \Leftrightarrow \varphi_{0}^{\text {exit }}=$ $\left(\frac{f}{B_{0} e^{g^{t}} e^{\beta(\sigma-1) t}}\right)^{\frac{1}{\sigma-1}}$ and similarly for the export market, i.e. $m^{x}\left(\varphi_{0}^{x}\right)=0 \Leftrightarrow$ $\varphi_{0}^{x}=\varphi_{0}^{e x i t}\left(\frac{f_{x}}{f \tau^{1-\sigma}}\right)^{\frac{1}{\sigma-1}}$. A firm entering at time $t$ with lottery component $\varphi_{0}$ earns net present value ${ }^{15}$ profits on the domestic market of

$$
\begin{aligned}
\pi\left(\varphi_{0}\right)= & \int_{t}^{t+m^{e x i t}\left(\varphi_{0}\right)}\left(B_{0} e^{g_{B} s} e^{\beta(\sigma-1) t} \varphi_{0}^{\sigma-1}-f\right) d s \\
= & B_{0} e^{\beta(\sigma-1) t} \varphi_{0}^{\sigma-1} \frac{1}{g_{B}}\left(e^{g_{B}\left(t+m^{e x i t}\left(\varphi_{0}\right)\right)}-e^{g_{B} t}\right)-f m^{e x i t}\left(\varphi_{0}\right) \\
= & B_{0} e^{\left[\beta(\sigma-1)+g_{B}\right] t} \varphi_{0}^{\sigma-1} \frac{1}{g_{B}}\left(e^{g_{B} t\left(1+\frac{g_{B}}{\beta(\sigma-1)}\right)}\left(\frac{B_{0}}{f}\right)^{\frac{g_{B}}{\beta(\sigma-1)}} \varphi_{0}^{\frac{g_{B}}{\beta}}-1\right) \\
& -f t\left(1+\frac{g_{B}}{\beta(\sigma-1)}\right)-f \ln \left(\frac{B_{0}}{f}\right)^{\frac{1}{\beta(\sigma-1)}}-\frac{1}{\beta} f \ln \varphi_{0}
\end{aligned}
$$

\footnotetext{
${ }^{15}$ Recall that the nominal interest rate is zero on the balanced growth path. Hence there is no discounting of future profits.
} 
and similarly on each of the $n$ export markets

$$
\begin{aligned}
\pi^{x}\left(\varphi_{0}\right)= & B_{0} \tau^{1-\sigma} e^{\left[\beta(\sigma-1)+g_{B}\right] t} \varphi_{0}^{\sigma-1} \frac{1}{g_{B}}\left(e^{g_{B} t\left(1+\frac{g_{B}}{\beta(\sigma-1)}\right)}\left(\frac{\tau^{1-\sigma} B_{0}}{f_{x}}\right)^{\frac{g_{B}}{\beta(\sigma-1)}} \varphi_{0}^{\frac{g_{B}}{\beta}}-1\right) \\
& -f_{x} t\left(1+\frac{g_{B}}{\beta(\sigma-1)}\right)-f_{x} \ln \left(\frac{\tau^{1-\sigma} B_{0}}{f_{x}}\right)^{\frac{1}{\beta(\sigma-1)}}-\frac{1}{\beta} f_{x} \ln \varphi_{0}
\end{aligned}
$$

Expected profits from entry at time $t$ is thus given by

$$
E\left[\pi\left(\varphi_{0}\right)+n \pi^{x}\left(\varphi_{0}\right)\right]=\int_{\varphi_{0}^{\text {exit }}}^{\infty} \pi\left(\varphi_{0}\right) d G\left(\varphi_{0}\right)+\int_{\varphi_{0}^{\exp \text { ort }}}^{\infty} n \pi^{x}\left(\varphi_{0}\right) d G\left(\varphi_{0}\right)
$$

where

$$
\begin{aligned}
& \int_{\varphi_{0}^{e x i t}}^{\infty} \pi\left(\varphi_{0}\right) d G\left(\varphi_{0}\right) \\
& =\int_{\varphi_{0}^{e x i t}}^{\infty}\left[\begin{array}{c}
\frac{B_{0} e^{\left[\beta(\sigma-1)+g_{B}\right] t} \varphi_{0}^{\sigma-1}}{g_{B}}\left(e^{\left.g_{B^{t}\left(1+\frac{g_{B}}{\beta(\sigma-1)}\right)}\left(\frac{B_{0}}{f}\right)^{\frac{g_{B}}{\beta(\sigma-1)}} \varphi_{0}^{\frac{g_{B}}{\beta}}-1\right)}\right. \\
-f t\left(1+\frac{g_{B}}{\beta(\sigma-1)}\right)-f \ln \left(\frac{B_{0}}{f}\right)^{\frac{1}{\beta(\sigma-1)}}-\frac{1}{\beta} f \ln \varphi_{0}
\end{array}\right] k \varphi_{0}^{-k-1} d \varphi_{0} \\
& =\left[\frac{e^{g_{B} t\left(1+\frac{g_{B}}{\beta(\sigma-1)}\right)}\left(\frac{B_{0}}{f}\right)^{\frac{g_{B}}{\beta(\sigma-1)}} k}{k-\left(\sigma-1+\frac{g_{B}}{\beta}\right)}\left(\varphi_{0}^{e x i t}\right)^{\frac{g_{B}}{\beta}}-\frac{k}{k-(\sigma-1)}\right] \frac{B_{0} e^{\left[\beta(\sigma-1)+g_{B}\right] t}\left(\varphi_{0}^{e x i t}\right)^{\sigma-1-k}}{g_{B}} \\
& -f\left[t\left(1+\frac{g_{B}}{\beta(\sigma-1)}\right)+\ln \left(\frac{B_{0}}{f}\right)^{\frac{1}{\beta(\sigma-1)}}\right]\left(\varphi_{0}^{e x i t}\right)^{-k}-\frac{1}{\beta} f \frac{1}{\left(\varphi_{0}^{e x i t}\right)^{k}}\left(\frac{1}{k}+\ln \left(\varphi_{0}^{e x i t}\right)\right) \\
& =\left[\frac{1}{g_{B}}\left(\frac{k}{k-\left(\sigma-1+\frac{g_{B}}{\beta}\right)}-\frac{k}{k-(\sigma-1)}\right)-\frac{1}{\beta k}\right] f\left(\varphi_{0}^{\text {exit }}\right)^{-k}
\end{aligned}
$$

and similarly

$$
\begin{aligned}
& \int_{\varphi_{0}^{\exp \text { ort }}}^{\infty} \pi^{x}\left(\varphi_{0}\right) d G\left(\varphi_{0}\right) \\
= & f_{x}\left(\varphi_{0}^{\exp \text { ort }}\right)^{-k}\left[\frac{1}{g_{B}}\left(\frac{k}{k-\left(\sigma-1+\frac{g_{B}}{\beta}\right)}-\frac{k}{k-(\sigma-1)}\right)-\frac{1}{\beta} \frac{1}{k}\right]
\end{aligned}
$$

The free entry condition $E\left[\pi\left(\varphi_{0}\right)+n \pi^{x}\left(\varphi_{0}\right)\right]=f_{e}$ can thus be written as

$$
\left[\frac{1}{g_{B}}\left(\frac{k}{k-\left(\sigma-1+\frac{g_{B}}{\beta}\right)}-\frac{k}{k-(\sigma-1)}\right)-\frac{1}{\beta k}\right]\left[f+n f_{x}\left(\frac{f_{x} \tau^{\sigma-1}}{f}\right)^{-\frac{k}{\sigma-1}}\right]\left(\varphi_{0}^{e x i t}\right)^{-k}=f_{e}
$$


which in turn implies that

$\varphi_{0}^{e x i t}=\left[\frac{1}{g_{B}}\left(\frac{k}{k-\left(\sigma-1+\frac{g_{B}}{\beta}\right)}-\frac{k}{k-(\sigma-1)}\right)-\frac{1}{\beta k}\right]^{\frac{1}{k}}\left[\frac{f+n f_{x}\left(\frac{f_{x} \tau^{\sigma-1}}{f}\right)^{-\frac{k}{\sigma-1}}}{f_{e}}\right]^{\frac{1}{k}}$

\section{Aggregation}

Labor demand of the cohort of age $m$ at time $t$ is given by

$$
\begin{aligned}
L_{t, m} & =M_{t-m}^{e}\left[\begin{array}{c}
\int_{\varphi_{e}^{e x i t}}^{\infty}\left(f+B_{t}(\sigma-1) \varphi^{\sigma-1}\right) d G_{t-m}(\varphi) \\
+n \int_{\varphi_{t}^{x}}^{\infty}\left(f_{x}+B_{t}(\sigma-1) \varphi^{\sigma-1} \tau^{1-\sigma}\right) d G_{t-m}(\varphi)
\end{array}\right] \\
& =M_{t-m}^{e}\left[\begin{array}{c}
f \bar{\varphi}_{t-m}^{k}\left(\varphi_{t}^{e x i t}\right)^{-k}+B_{t}(\sigma-1) \frac{k}{k-(\sigma-1)} \bar{\varphi}_{t-m}^{k}\left(\varphi_{t}^{e x i t}\right)^{\sigma-1-k} \\
+n\left(f_{x} \bar{\varphi}_{t-m}^{k}\left(\varphi_{t}^{x}\right)^{-k}+B_{t}(\sigma-1) \tau^{1-\sigma} \frac{k}{k-(\sigma-1)} \bar{\varphi}_{t-m}^{k}\left(\varphi_{t}^{x}\right)^{\sigma-1-k}\right)
\end{array}\right] \\
& =M_{t-m}^{e}\left(\frac{\bar{\varphi}_{0}}{\varphi_{0}^{e x i t}}\right)^{k} e^{-m \beta k} f\left[1+n \tau^{1-\sigma}\left(\frac{f_{x}}{f \tau^{1-\sigma}}\right)^{\frac{\sigma-1-k}{\sigma-1}}\right] \frac{k \sigma-(\sigma-1)}{k-(\sigma-1)}
\end{aligned}
$$

Let the mass of entrants grow at rate $g_{M e}$ then

$$
\begin{aligned}
L_{t, m} & =M_{0}^{e} e^{g_{M^{e}}(t-m)}\left(\frac{\bar{\varphi}_{0}}{\varphi_{0}^{e x i t}}\right)^{k} e^{-m \beta k} f\left[1+n \tau^{1-\sigma}\left(\frac{f_{x}}{f \tau^{1-\sigma}}\right)^{\frac{\sigma-1-k}{\sigma-1}}\right] \frac{k \sigma-(\sigma-1)}{k-(\sigma-1)} \\
& =M_{0}^{e}\left(\frac{\bar{\varphi}_{0}}{\varphi_{0}^{e x i t}}\right)^{k} f\left[1+n \tau^{1-\sigma}\left(\frac{f_{x}}{f \tau^{1-\sigma}}\right)^{\frac{\sigma-1-k}{\sigma-1}}\right] \frac{k \sigma-(\sigma-1)}{k-(\sigma-1)} e^{g_{M^{e}} t} e^{-m\left(\beta k+g_{M^{e}}\right)}
\end{aligned}
$$

implying at total labor demand at time $t$ of

$$
\begin{aligned}
L_{t} & =M_{0}^{e} e^{g_{M^{e}} t} f_{e}+\int_{0}^{\infty} L_{t, m} d m \\
& =M_{0}^{e} e^{g_{M^{e}} t}\left(f_{e}+\left(\frac{\bar{\varphi}_{0}}{\varphi_{0}^{e x i t}}\right)^{k} f\left[1+n \tau^{1-\sigma}\left(\frac{f_{x}}{f \tau^{1-\sigma}}\right)^{\frac{\sigma-1-k}{\sigma-1}}\right]\left(1+\frac{(\sigma-1) k}{k-(\sigma-1)}\right) \frac{1}{\beta k+g_{M^{e}}}\right)
\end{aligned}
$$

However as $L_{t}=L$ for all $t$ it follows that $g_{M^{e}}=0$ which implies that $M_{t}^{e}=M^{e}$ for all $t$ on the balanced growth path, where

$$
\begin{aligned}
M^{e} & =L\left(f_{e}+\left(\frac{\bar{\varphi}_{0}}{\varphi_{0}^{\text {exit }}}\right)^{k} f\left[1+n \tau^{1-\sigma}\left(\frac{f_{x}}{f \tau^{1-\sigma}}\right)^{\frac{\sigma-1-k}{\sigma-1}}\right]\left(1+(\sigma-1) \frac{k}{k-(\sigma-1)}\right) \frac{1}{\beta k}\right)^{-1} \\
& =\frac{\sigma-1}{\sigma} \frac{1}{k} \frac{L}{f_{e}}
\end{aligned}
$$


Now we can compute the mass of active firms on the balanced growth path as

$$
M=\int_{0}^{\infty} M_{t-m}^{e}\left(\int_{\varphi_{t}^{\text {exit }}}^{\infty} d G_{t-m}(\varphi) d \varphi\right) d m=M^{e}\left(\frac{\bar{\varphi}_{0}}{\varphi_{0}^{\text {exit }}}\right)^{k} \frac{1}{\beta k}
$$

Turning to the price index, we have that

$$
\begin{aligned}
P_{t} & =\left[\begin{array}{c}
M_{t} \int_{\varphi_{t}^{\text {exit }}}^{\infty}\left(\frac{\sigma}{\sigma-1} \frac{1}{\varphi}\right)^{1-\sigma} k\left(\varphi_{t}^{\text {exit }}\right)^{k} \varphi^{-k-1} d \varphi \\
+n M_{t} \int_{\varphi_{t}^{x}}^{\infty}\left(\frac{\sigma}{\sigma-1} \frac{1}{\varphi} \tau\right)^{1-\sigma} k\left(\varphi_{t}^{\text {exit }}\right)^{k} \varphi^{-k-1} d \varphi
\end{array}\right]^{\frac{1}{1-\sigma}} \\
& =M^{\frac{1}{1-\sigma}} \frac{\sigma}{\sigma-1}\left[\frac{k}{k-(\sigma-1)}\left(1+n \tau^{1-\sigma}\left(\frac{f_{x}}{f \tau^{1-\sigma}}\right)^{\frac{\sigma-1-k}{\sigma-1}}\right)\right]^{\frac{1}{1-\sigma}}\left(\varphi_{t}^{\text {exit }}\right)^{-1}
\end{aligned}
$$

and thus we have that $\frac{\dot{P}_{t}}{P_{t}}=-\frac{\dot{\varphi}_{t}^{\text {exit }}}{\varphi_{t}^{\text {exit }}}=-\beta$. This in turn implies that $B_{t}=$ $\frac{1}{\sigma-1}\left(\frac{\sigma}{\sigma-1}\right)^{-\sigma} R P_{t}^{\sigma-1}$ grows at rate $-\beta(\sigma-1)$, i.e. $g_{B}=-\beta(\sigma-1)$. Using this, we have

$$
\begin{aligned}
M^{e} & =\frac{\sigma-1}{\sigma} \frac{1}{k} \frac{L}{f_{e}} \\
M & =\frac{L}{\sigma f} \frac{k-(\sigma-1)}{k}\left(1+n \frac{f_{x}}{f}\left(\frac{f_{x} \tau^{\sigma-1}}{f}\right)^{-\frac{k}{\sigma-1}}\right)^{-1} \\
P_{t} & =\frac{\sigma}{\sigma-1}\left(\frac{L}{\sigma f}\right)^{\frac{1}{1-\sigma}} \frac{e^{-\beta t}}{\varphi_{0}^{\text {exit }}} \\
\varphi_{0}^{\text {exit }} & =\left(\frac{(\sigma-1)}{k-(\sigma-1)} \frac{f}{f_{e}} \frac{1}{\beta k}\right)^{\frac{1}{k}}\left(1+n \frac{f_{x}}{f}\left(\frac{f_{x} \tau^{\sigma-1}}{f}\right)^{-\frac{k}{\sigma-1}}\right)^{\frac{1}{k}}
\end{aligned}
$$

Summing up, we have a balanced growth path with the properties $\frac{\dot{B}_{t}}{B_{t}}=$ $-\beta(\sigma-1), \frac{\dot{P}_{t}}{P_{t}}=-\beta, \frac{\dot{\varphi}_{t}^{\text {exit }}}{\varphi_{t}^{\text {exit }}}=\frac{\dot{\varphi}_{t}^{x}}{\varphi_{t}^{x}}=\frac{\dot{\bar{\varphi}}_{t}}{\bar{\varphi}_{t}}=\beta, \frac{\dot{M}_{t}}{M_{t}}=\frac{\dot{M}_{t}^{e}}{M_{t}^{e}}=0$. 


\section{References}

Aghion, P. and R. Griffith (2005). Competition and Growth, MIT Press, Cambridge.

Allessandria, G. and H. Choi (2011). Establishment Heterogeneity, Exporter Dynamics, and the Effects of Trade Liberalization. FRB of Philadelphia Working Paper No. 11-19.

Arkolakis, C. (2009). A Unified Theory of Firm Selection and Growth. CESIFO working paper No. 2679.

Atkeson, A. and A. T. Burstein (2010). Innovation, Firm Dynamics, and International Trade, Journal of Political Economy, Vol. 118, pp. 433$484 .$.

Baldwin, R. E. and F. Robert-Nicoud (2007). Trade and Growth with Heterogeneous Firms, Journal of International Economics, Vol. 74 (1), pp. 21-34.

Boucekkine, R., O. Licandro, L.A. Puch and F. del Rio (2005). Vintage capital and the dynamics of the AK model, Journal of Economic Theory, Vol. 120(1), pp. 39-72.

Boucekkine, R., F. del Rio and O. Licandro, L.A. Puch and (2003). Embodied Technological Change, Learning-by-doing and the Productivity Slowdown, Scandinavian Journal of Economics, Vol. 105(1), p.87-98.

Boucekkine, R., D. de la Croic and O. Licandro (2011). Vintage Capital Growth Theory: Three Breakthroughs, Barcelona GSE Working Paper Series. No. 565.

Burstein, A. and M. J. Melitz (2011). Trade Liberalization and Firm Dynamics, NBER Working Paper no. 16960

Campbell, J.R. (1997). Entry, Exit, Embodied Technology, and Business Cycles, NBER Working Paper No. 5955.

Caves, R. (1998). Industrial Organization and New Findings on the Turnover and Mobility of Firms, Journal of Economic Literature, Vol. 36(4), pp. 1947-1982.

Chaney, T. (2008). Distorted Gravity: Heterogeneous Firms, Market Structure, and the Geography of International Trade, American Economic Review, Vol. 98 , pp. 1707-1721.

Colantone, I and L. Sleuwaegen (2010). International Trade, Exit and entry: A cross-country and industry analysis, Journal of International Business Studies, Vol 41(7), pp. 1240-1257.

Comin, D. and B. Hobijn (2010). An Exploration of Technology Diffusion, American Economic Review, Vol. 100 (5), pp. 2031-2059.

Comin, D., B. Hobijn and E. Rovito (2008). Technology usage lags, Journal 
of Economic Growth, Vol. 13, pp. 237-256.

Costantini, J.A. and M.J. Melitz (2009). The Dynamics of Firm-Level Adjustments to Trade Liberalization. In The Organization of Firms in a Global Economy, Harved University Press.

Dasgupta, P. and J. Stiglitz (1981). Entry, Innovation, Exit: Towards a Dynamic Theory of Oligopolistic Industrial Structure. European Economics Review, Vol. 15, pp. 137-158.

Dunne, T., M. Roberts and L. Samuelson (1988). Patterns of Firm Entry and Exit in United-States Manufacturing-Industries. Rand Journal of Economics, Vol. 19(4), pp. 495-515.

Eaton, J., S. Kortum and F Kramarz (forthcoming). An Anatomy of International trade: Evidence from French Firms. Econometrica, forthcoming.

Ederington, J. and P. McCalman (2009). International Trade and Industrial Dynamics. International Economic Review, Vol. 50(3), pp. 961-989.

Farinas, J.C. and S. Ruano (2005). Firm Productivity, heterogeneity, sunk costs and market selection. International Journal of Industrial Organization, Vol. 23, pp. 505-534.

Foster, L., J. Haltiwanger and C.J. Krizan (2001). Aggregate Productivity Growth - Lessons from Microeconomic Evidence, in: New Developments in Productivity Analysis eds. C.R. Hulten, E.R. Dean and M.J. Harper. University of Chicago Press.

Gabler A. and O. Licandro (2007). Endogenous Growth through Selection and Imitation, Economics Working Papers ECO2007/26, European University Institute.

Ghironi, F. and M. J. Melitz (2005). International Trade and Macroeconomic Dynamics with Heterogeneous Firms, The Quarterly Journal of Economics, Vol. 120, pp. 865-915.

Greenaway, D. and R. Kneller (2007). Firm Heterogeneity, Exporting and Foreign Direct Investment, The Economic Journal Vol 117, pp. 134161.

Greenaway D. and R. Kneller (2008). Exporting, productivity and agglomeration, European Economic Review, Vol. 52, pp. 919-939.

Haruyama, T. and L. Zhao (2008). Trade and Firm Heterogeneity In A Quality-Ladder Model of Growth, Research Institute for Economics \& Business Administration, Kobe University, Discussion Paper no. 223.

Helpman, E., M.J. Melitz and S.R. Yeaple (2004). Export Versus FDI with Heterogeneous Firms. American Economic Review, Vol. 94(1), pp. 300-316.

Hopenhayn, H. (1992). Entry, Exit and Firm Dynamics in the Long Run, Econometrica Vol. 60 (5), pp. 1127-1150 
Impullitti, G. and O. Licandro (2010). Trade, Firm selection, and innovation: the competition channel, UFAE and IAE Working Papers 841.10.

Irarrazabal, A. and L.D. Opromolla (2008). A Theory of Entry and Exit into Exports Markets, Banco de Portugal, working paper 2008-20.

Jovanovic, B. (1982). Selection and the Evolution of Industry. Econometrica, Vol. 50(3), pp. 649-670.

Klepper, S. (2002). Firm Survival and the Evolution of Oligopoly. Rand Journal of Economics, Vol. 33(1), pp. 37-61.

Levitt, B. and J.G. March (1988). Organizational Learning. Annual Review of Sociology, Vol. 14, pp. 319-340.

Luttmer, E.G. (2007). Selection, Growth, and the size distribution of firms. Quarterly Journal of Economics, Vol. 122(3), pp. 1103-1144.

Melitz, M.J. (2003). The Impact of Trade on Intra-industry Reallocations and Aggregate Industry Productivity. Econometrica, Vol. 71 (6), pp. 1695-1725.

Olley, G.S. and A. Pakes (1996). The Dynamics of Productivity in the Telecommunications Equipment Industry. Econometrica, Vol. 64 (6), pp. 1263-1297.

Ruhl, K.H. (2008). The International Elasticity Puzzle. University of TexasAustin, mimeo.

Pflüger, M. and S. Russek (2011). Business Conditions and Default Risks across Countries. IZA Discussion Paper No. 5541.

Schröder, P.J.H., and A. Sørensen (2011). Second Thoughts on the Exporter Productivity Premium. Canadian Journal of Economics, forthcoming.

Stigler, G. (1958). The Economies of Scale, Journal of Law and Economics, Vol.1, pp. 54-71.

Wagner, J. (2007). Exports and Productivity: A Survey of the Evidence from Firm-level Data, The World Economy Vol. 30, pp. 60-82.

Wagner, J. (2011). International Trade and Firm Performance: A survey of empirical Studies since 2006. University of Lüneburg Working Paper Series in Economics. No. 210. 


\section{Economics Working Paper}

2011-04: $\quad$ Mikkel Nørlem Hermansen: Non-existence of Steady State Equilibrium in the Neoclassical Growth Model with a Longevity Trend

2011-05: John Kennes, Daniel Monte and Norovsambuu Tumennasan: The Daycare Assignment Problem

2011-06: Rene Saran and Norovsambuu Tumennasan: Whose Opinion Counts?

2011-07: Mark Strøm Kristoffersen: Liquidity Constraints and Fiscal Stabilization Policy

2011-08: Martin Paldam: The cycle of development in Africa. A story about the power of economic ideas

2011-09: Thorvardur Tjörvi Ólafsson, Ásgerdur Pétursdóttir and Karen Á. Vignisdóttir: Price setting in turbulent times. Survey evidence from Icelandic firms

2011-10: Torben M. Andersen: Social policies and activation in the Scandinavian welfare model: the case of Denmark

2011-11: Norovsambuu Tumennasan: To Err is Human: Implementation in Quantal Response Equilibria

2011-12: Norovsambuu Tumennasan: Do Contracts Help? A Team Formation Perspective

2011-13: Norovsambuu Tumennasan: Quantity Precommitment and Price Matching

2011-14: Anette Primdal Kvist, Helena Skyt Nielsen and Marianne Simonsen: The effects of Children's ADHD on Parents' Relationship Dissolution and Labor Supply

2011-15: Hristos Doucouliagos and Martin Paldam: The robust result in meta-analysis of aid effectiveness: A response to Mekasha and Tarp

2011-16: Helena Skyt Nielsen and Beatrice Schindler Rangvid: The Impact of Parents' Years since Migration on Children's Academic Achievement

2011-17: $\quad$ Philipp J.H. Schröder and Allan Sørensen: Firm Exit, Technological Progress and Trade 